\title{
Clinico-Ultrasonographic Profile of Ectopic Pregnancy in Western Nepal
}

\author{
Gurung SD ${ }^{1}$, Sharma $\mathbf{P}^{2}$ \\ ${ }^{1}$ Department of Obstetric and Gynaecology, Manipal Teaching Hospital, Pokhara, Nepal \\ ${ }^{2}$ Department of Radiology and Imaging, Manipal Teaching Hospital, Pokhara, Nepal
}

Received: March 20, 2018

Accepted: April 30, 2018

Published: June 30, 2018

Cite this paper:

Gurung SD, Sharma P. Clinico-Ultrasonographic Profile of Ectopic Pregnancy in Western Nepal. Nepalese Journal of Radiology 2018;8(11):2-6.http://dx.doi.org/10.3126/njr.v8i1.20438

\begin{abstract}
Introduction: Ectopic pregnancy (EP) is one of the major complications in first trimester pregnancy, resulting in increased maternal morbidity and mortality. It accounts for $1.3-2.4 \%$ of all pregnancies. Previously, though laparoscopy was considered as the gold standard for diagnosis of ectopic pregnancy, due to availability of high resolution ultrasound, it has become the first line investigation for the diagnosis of ectopic pregnancy.
\end{abstract}

Methods: It is a prospective study conducted in Manipal Teaching Hospital, Pokhara, from January 2015 till December 2017. All the cases diagnosed with ectopic pregnancy were included in the study. Ultrasonological and intraoperative findings were recorded. Data was analyzed using SPSS (VERSION 16).

Results: Twenty six patients were diagnosed with ectopic pregnancies. The incidence was $0.35 \%$. It was most common among the reproductive age group between $20-40$ years with mean age of 30.50 years. Pelvic inflammatory disease $(n=10,38.5 \%)$ was considered as risk factor. Radiological finding of Type III ectopic pregnancy $(n=21,80.8 \%)$ was the most common type.

Conclusion: Ectopic pregnancy is common among reproductive age group with previous history of pelvic inflammatory disease. Type III is the most common type.

Key words: Abdominal Pain ; Pregnancy, Ectopic; Ultrasonography

\section{INTRODUCTION}

The word ectopic pregnancy is derived from the Greek word "ektopos", which means "out of place". ${ }^{1}$ Ectopic pregnancy (EP), is the condition where the blastocyst is implanted outside the uterine cavity. It is one of the major cause of maternal morbidity and mortality in early trimester and responsible for $80 \%$ of

Correspondence to: Dr. Sangeeta Devi Gurung Department of Obstetric and Gynaecology Manipal Teaching Hospital

Pokhara, Nepal

Email: gurungsangeeta2018@gmail.com maternal deaths that occur in early pregnancy. ${ }^{2}$ The incidence of EP has been reported to be $1.3-2.4 \% .^{3}$ 
Timely diagnosis of EP is essential as it may present as a surgical emergency. The clinical triad of EP are amenorrhea followed by vaginal bleeding, abdominal pain and a tender adnexal mass. ${ }^{4}$ Before the era of ultrasonography, EP was a life threatening condition and diagnosis was made at the time of surgery. Before 1970 , more than $80 \%$ of the patients with EP were diagnosed only after rupture and more than $50 \%$ collapsed. ${ }^{5,6}$ Fortunately, with the advent of ultrasonography, early diagnosis and management of EP has decreased the incidence of maternal morbidity and mortality.

\section{METHODS}

This is a prospective study, which was carried out in the Obstetrics department of Manipal Teaching Hospital, Pokhara, from January 2015 to December 2017. All the patients with clinical suspicion of ectopic pregnancy were send for ultrasonography of abdomen and pelvis in the department of Radiodiagnosis. Urine for $\beta$ human chorionic gonadotropin (HCG) was done in all the patients. Serum $\beta$ HCG level was estimated as when required. Ultrasonography was conducted by a Radiologist. Ectopic pregnancy was diagnosed based on urine for $\beta$ HCG, Ultrasonographic findings, intraoperative findings and clinical outcome. Almost all of the patients underwent laparotomy. Clinical data, Ultrasonography findings and intraoperative findings were recorded. The data was analyzed using SPSS (Version 16). Clearance from institutional ethical review board was obtained prior to the study.

\section{RESULTS}

During the study period, 125 patients were suspected of ectopic pregnancy. Ultrasonography revealed ectopic pregnancy in 26 patients, which were included for statistical analysis. During the study period, there were seven thousand three hundred and fifty four deliveries. The incidence of EP in this study was only $0.35 \%$.

The age of the patients ranged from 20-42 years with mean age of 30.50 years (Table 1 ). The gestational age ranged from 15 days to 91 days with mean age of 43 days. The parity of the patient ranged from 1-6 with majority being $3(n=7,29.9 \%)$.

Ten patients with ectopic pregnancy had PID, three had history of dilatation and curettage, two had history of use of oral contraceptive pills, one had history of IUCD insertion and in ten patients no risk factors were identified (Table 2)

Ultrasonographically, ruptured ectopic with hemoperitoneum was the most common type and was detected in twenty one patients (Table 3 ). Majority of the patients diagnosed with hemoperitoneum had blood loss up to 1000 $\mathrm{ml}$ (Table 4). Right sided tubal rupture was more common than left side and were seen in fifteen patients.

Table 1: Age distribution of the patients

\begin{tabular}{|l|l|l|l|} 
Age & $\mathbf{N}=\mathbf{2 6}$ & Percentage & \multirow{2}{*}{ Mean=30.50 } \\
\hline$<20$ & 1 & 3.8 \\
\hline $21-40$ & 24 & 92.3 & \\
\hline$>40$ & 1 & 3.8 & \\
\hline
\end{tabular}

Table 2: Distributions of patients according to predisposing factors

\begin{tabular}{|l|l|l|}
\hline Predisposing Factors & Number & Percentage \\
\hline None & 10 & $38.5 \%$ \\
\hline IUCD & 1 & $3.8 \%$ \\
\hline OCP & 2 & $7.7 \%$ \\
\hline Dilatation and Curettage & 3 & $11.5 \%$ \\
\hline PID & 10 & $38.5 \%$ \\
\hline Total & 26 & $100 \%$ \\
\hline
\end{tabular}


Table 3: Distribution of Ectopic Pregnancy according to USG findings

\begin{tabular}{|l|l|l|l|}
\hline Ultrasound Findings & Number & Percentage \\
\hline Type I & Unruptured live ectopic with heart beat & 1 & $3.8 \%$ \\
\hline Type II & Early embryonic demise without rupture & 3 & $11.5 \%$ \\
\hline Type III & Ruptured ectopic with hemoperitoneum & 21 & $80.8 \%$ \\
\hline Type IV & No sonological findings of ectopic & 1 & $3.8 \%$ \\
\hline
\end{tabular}

Table 4: Distribution of patients according to the amount of blood loss

\begin{tabular}{|l|l|l|} 
Blood Loss & Number of Patients & Percentage \\
\hline$<500 \mathrm{ml}$ & 9 & $34.6 \%$ \\
\hline $501-1000 \mathrm{ml}$ & 9 & $34.6 \%$ \\
\hline $1001-1500 \mathrm{ml}$ & 5 & $19.2 \%$ \\
\hline $1501-2000 \mathrm{ml}$ & 2 & $7.7 \%$ \\
\hline$>2000 \mathrm{ml}$ & 1 & $3.8 \%$ \\
\hline
\end{tabular}

\section{DISCUSSION}

Ectopic pregnancy is the pregnancy occurring outside the uterine cavity and is one of the major cause of maternal morbidity and mortality in the early trimester. ${ }^{2}$ The trend of $\mathrm{EP}$ is rising due to early diagnosis and increase in the rates of sexually transmitting diseases, especially the Chlamydial infection. ${ }^{7}$

In this study, the majority of the cases were in the age group 21-40 years. This is similar to the study done in other parts of the country which showed peak age of 28-32 years in a study conducted in Kathmandu Model hospital $^{8}$ and age group of 31-35 years in the study conducted in Nepalgunj Medical college. ${ }^{9}$

The incidence of EP in this study was only $0.35 \%(\mathrm{n}=26$, out of seven thousand, three hundred and fifty four deliveries). This incidence is low as compared to the study done by Mikolajizyk RT et al which showed the incidence to be $1.3-2.4 \%{ }^{3}$ According to the American College of Obstetrics and Gynaecologists (2008), of all the pregnancies in the United States, two percent of them are ectopic. ${ }^{10}$

The risk factors for EP is multifactorial but however in half of the women diagnosed with EP, no recognized risk factors has been identified. ${ }^{11}$ In this study also, no risk factors were identified among $38.5 \%$ of the patients $(n=10)$. The postulated mechanism for EP may be anatomical and/or functional leading to impaired tubal motility, tubal obstruction, ciliary dysfunction and chemotactic factors that lead to tubal implantation. ${ }^{11}$ women with previous history of pelvic inflammatory disease are at risk of EP. ${ }^{12,13,14}$ Similarly, rising incidence in pelvic inflammatory disease, mainly the Chlamydial infection has also been associated with EP. ${ }^{7}$ This study also showed that $38.5 \%(n=10)$ of the patients had pelvic inflammatory disease. Intrauterine contraceptive device (IUCD) reduces the risk of EP but however if the woman gets pregnant, she is at increased risk of having an EP and the incidence being 1 in 100 of all pregnancies. ${ }^{15}$ In this study, only one patient had history of IUCD insertion.

In this study, transvaginal or transabdominal ultrasound was used for the diagnosis of EP. Previously, laparoscopy was considered as the gold standard for the diagnosis of EP. At present, due to the increased availability of high resolution transvaginal and transabdominal ultrasound, $80 \%$ of EP are diagnosed before they get ruptured and 50\% of EP are diagnosed before the women are symptomatic. ${ }^{16}$ Depending upon the pelvic ultrasound four spectral patterns of ectopic pregnancy have been described. ${ }^{17}$ 
Type 1: Unruptured live ectopic with heart beat Type 2: Early embryonic demise without rupture/embryonic structures/heartbeat

Type 3: Ruptured ectopic with blood in pelvis Type 4: No sonological sign of ectopic pregnancy

In this study, $80.8 \%(n=21)$ had Type III EP. This study is similar to the study conducted by Kaur N and Aryal S which showed 58.82\% were ruptured ectopic with hemoperitoneum. ${ }^{18}$

Surgical treatment is the treatment of choice for EP if the patient is hemodynamically unstable, ruptured ectopic, diameter of the gestational sac more than $4 \mathrm{~cm}$ on ultrasonography or pain persisting beyond 24 hours. ${ }^{19}$ However, medical management can be done in case of unruptured EP with gestational sac less than $4 \mathrm{~cm}$ and hemodynamically stable patient. Different agents like systemic and local methotrexate(MTX), local potassium chloride, hyperosmolar glucose, prostaglandins, danazol, etoposide and mifepristone have been used but the current therapies focus primarily on MTX treatment. ${ }^{20,21}$ MTX is a folic acid antagonist. Its single dose regimen is more convenient than multiple dose regimen but has higher risk of persistent EP. So follow up with serial ultrasound and serum concentration of human chorionic gonadotropin is required. ${ }^{22}$ One patient, in this study, was treated with a single dose of MTX. Serial ultrasound and monitoring of the human chorionic gonadotropin was done and the EP was resolved. However, there was no mortality in this study period.

\section{CONCLUSION}

This study showed that ectopic pregnancy is common in women in reproductive age group. Those with history of pelvic inflammatory disease are at risk of developing ectopic pregnancy and Type III is the most common type.

\section{CONFLICT OF INTEREST}

None

\section{SOURCES OF FUNDING}

None

\section{REFERENCES}

1. Kirk E, Bourne T. Ectopic pregnancy. Obstet Gynaecol Reprod Med 2011;21(7):207-211. https://doi.org/10.1016/j. ogrm.2011.04.003

2. Confidential Enquiries Into Maternal Deaths. Why mothers die 19971999: The fifth report of the Confidential Enquiries into Maternal Deaths in the United Kingdom. No. 5. Regent's Park, London: RCOG Press 2001.

3. Mikolajizyk RT, Kraut AA, Garbe E. Evaluation of pregnancy outcome records in the Gernman Pharmacoepidemiological Research Database. Pharmacoepidemiol Drug Saf 2013;22:873-880. https://doi.org/10.1002/pds.3467

4. Pearson J, Rooyen J. John Hopkins manual of obstetric and gynaecology. $3^{\text {rd }}$ ed. Philadelphia: Lippincott Williams and Wilkins 2007:p303-311.

5. BulentB, Nezhat C, Nezhat F. Management of the ectopic pregnancy. In Nezhat's Operative gynecologic Laparoscopy and Hysterescopy. Cambridge:Cambridge University press 2008:p215.

6. Breen JL: A 21 year survey of 654 ectopic pregnancies. $A m \quad J$ Obstet Gynaecol 1970:106;1004. https://doi.org/10.1016/S00029378(16)34087-X

7. Hillis SD, Owens LM, Marchbanks PA et al. Recurrent chlamydial infections increase the risks of hospitalization for ectopic pregnancy and pelvic inflammatory disease. $\mathrm{Am}$ J Obstet Gynecol 1997;176:103-107. https://doi.org/10.1016/S00029378(97)80020-8 
8. PradhanHK,DangolG,KarkiAetal.Profile of Ectopic Pregnancy at Kathmandu Model Hospital. Nepal Journal of Obstetrics and Gynaecology 2015;10(2):10-13. http://dx.doi.org/10.3126/njog. $\underline{\mathrm{v} 10 \mathrm{i} 2.14328}$

9. Sharma P, Sing BP. Ectopic pregnancy in Nepalgunj Medical College. J Inst Med 2011;33(2):1. Available from: http://www.jiom.com.np/index.php/ jiomjournal/article/view/517/479 [Accessed 15th Jan 2018].

10. William D, William LL. Recent Advances in Obstetrics and Gynaecology. 24 $4^{\text {th }}$ ed. The Royal Society of Medicine Press 2008:p288.

11. Manon LL, Meeks GR: Ectopic pregnancy: History, incidence, epidemiology and risk factors. Clin Obstet Gynecol 2012;55:376-386. ht tps://doi.org/10.1097/ GRF.0b013e3182516d7b

12. Marchbanks PA, Annegers JF, Conlam $\mathrm{CB}$ et al. Risk factors for ectopic pregnancy. A population based study. JAMA 1988;351:1115-1120. https://doi.org/10.1001/jama.259.12.1823

13. Strandell A, Thorburn J, Hamberger I. Risk factors for ectopic pregnancy in assisted reproduction. Fertil Steril 1999;71:282-286. https://doi.org/10.1016/S0015$\underline{0282(98) 00441-5}$

14. Westrom L, Bengtsson LPH, Mardh PA. Incidence, trends and risks of ectopic pregnancy in a population of women. BMJ 1981;282:15-18. https://doi.org/10.1136/bmj.282.6257.15

15. Bouyer J, Rachon E, Germain E et al. Risk factors for extrauterine pregnancy in women using an intrauterine device. Fertil Steril 2000;74:899-908. https://doi. org/10.1016/S0015-0282(00)01605-8
16. Bignardi T, Alhamdan D, Condous G. Is Ultrasound the new gold standard gor the diagnosis of ectopic pregnancy? Semin Ultrasound CT MR 2008;29(2):114-120. https://doi.org/10.1053/j.sult.2008.01.001

17. Danhert W. Radiology Review Manual. $6^{\text {th }}$ ed. New Delhi: Lippincott Williams and Wilkins 2007.

18. Kaur N, Aryal S. Clinical Study of Ectopic pregnany in a Tertiary Care Hospital in Nepal. J Lumbini Med Coll 2014;2(2):3740.

19. Buster JE, Carson SA. Ectopic pregnancy; new advances in diagnosis and treatment. Curr Opinion Obstet Gynecol 1995;7(3):168-176. Available from: https://www.ncbi.nlm. nih.gov/pubmed/7647267[Accessed 15th Jan 2018].

20. Raughley MJ, Frishman GN. Local treatment of ectopic pregnancy. Semin Reprod Med 2007;25(2):99-115. https://doi.org/10.1055/s-2007-970049

21. Hajenius PJ, Mol BWJ, Ankum WM et al. Systemic and local medical therapy of tubal pregnancy. In:Timmerman D, Deprest J, Bourne T (eds) Ultrasound and endoscopic surgery in obstetrics and gynecology. A combined approach to diagnosis and treatment. Springer, London. ISBN 3540762124.

22. PisarskaMD,CarsonSA,BusterJE.Ectopic pregnancy. Lancet 1998;351:1115-1120. https://doi.org/10.1016/S0140$\underline{\text { 6736(97)11476-3 }}$ 